\title{
Morir de pie. Una aproximación a los derechos humanos a partir de dos novelas latinoamericanas
}

\section{To die with dignity. An approach to Human Rights based on two Latin American novels}

\author{
Malvina Guaraglia Pozzo \\ Universidad de la República, Uruguay
}

Resumen: El artículo plantea la posibilidad de leer los derechos humanos desde una perspectiva cultural, haciendo hincapié en su dimensión ética, como herramientas de construcción de identidades políticas y sociales. Desde esta premisa, y partiendo de un campo nuevo de estudios, se postula la existencia de una larga genealogía de textos de denuncia que han articulado los principios éticos de los derechos humanos en los espacios públicos nacionales de las sociedades latinoamericanas. Asimismo, a través del análisis ejemplificativo de dos novelas, se estudian las distintas estrategias retóricas que pueden estar en la base de esa articulación.

Palabras clave: derechos humanos, literatura latinoamericana, narrativas de denuncia, sujetos subalternos, sujetos de derecho.

Abstract: The article advances the possibility of reading Human Rights from a cultural perspective, making emphasis on their ethical dimension, and as tools for the construction of political and social identities. From this standpoint, and also from a new field of research, it proposes the existence of a long genealogy of social criticism texts that have articulated the ethical principles of Human Rights in national public 
spaces of Latin American societies. Also, through the exemplary study of two novels, the articles study the rhetoric strategies that may be on the basis of that articulation.

Keywords: Human Rights, Latin American literature, Narrative of social criticism, Subaltern subjects, Subjects of rights.

Recibido: 24 de diciembre de 2017 Aprobado: 3 de abril de 2018

\section{Introducción: los derechos humanos como cultura}

$\mathrm{D}$ urante los ańos 2015 y 2016 un equipo de investigadores del Departamento de Literatura latinoamericana y uruguaya de la Universidad de la República llevamos adelante el proyecto de investigación Raices latinoamericanas de los derechos humanos: la literatura como fuente. Nos sentíamos profundamente interesados en entender las vinculaciones entre distintas expresiones de la literatura del continente y la tradición de los derechos humanos, porque numerosos textos daban cuenta de una concepción de la justicia y de la dignidad de la vida humana que remitían inmediatamente a dicha tradición, como si ambos discursos abrevaran de las mismas fuentes de pensamiento, o como si determinadas modalidades literarias fueran en sí mismas una práctica de derechos humanos en otro código. Para poder entender el mecanismo por el cual la literatura construía a determinados sujetos como poseedores de dignidad, y del derecho a tener derechos, se hizo evidente que necesitábamos una lectura cultural de los derechos humanos que los desencastrara del paradigma legalista con el que son abordados generalmente, para restituirlos al campo de fuerzas de la esfera social, pública, en la que circulan y adquieren sentido antes, durante y después de constituirse en disposiciones jurídicas. Esta dimensión cultural, sin embargo, y al decir de Remedi, "appears -if at allas an item of residual importance, a deviation from fundamental 
issues, and a luxury that we cannot afford, thus reinforcing the notion that culture is something ornamental" (Remedi, 2009: 59).

Trabajar desde esa mirada cultural nos llevó a abordar la tradición de los derechos humanos como un particular lenguaje normativo que, en especial a partir del siglo XVIII, se volvió cada vez más ineludible en la constitución del sujeto moderno. Este sujeto, definido en virtud de su propia humanidad, fue también delimitado a partir de su relación con los otros y con el poder. Los derechos humanos plantearon así un modelo de humanidad, de sociabilidad y de organización política. Resultaba fundamental, entonces, entender la serie de premisas según las cuales los derechos humanos postulan qué significa ser 'humano', algo que sólo puede adquirir sentido y contenido por referencia a unos marcos culturales previos. Más importante aún, y tal como lo plantea Amartya Sen, es que se trata de un conjunto de 'potentes demandas morales' (Sen, 2004: 327) que conllevan la necesidad de dilucidar el tipo de compromisos y obligaciones que es razonable adoptar en relación a los demás y, por tanto, las formas de reciprocidad deseables entre personas distintas entre sí que deben, no obstante, considerarse iguales en un sentido fundamental. En el centro de los derechos humanos se encuentra, en consecuencia, la cuestión del reconocimiento de los otros como fundante de un tipo particular de comunidad -esto es, una ética específica de la convivencia- y una forma determinada de concebir y ejercer el poder.

La delicada cuestión de cómo y hasta dónde es posible y "correcto" delimitar esta comunidad de iguales -nacional, occidental, global, universal- tiene que ver precisamente con la dificultad para definir un único sujeto que pueda funcionar como fuente de derechos en todas ellas, y con la extensión que esa reciprocidad moral debería alcanzar basándose en una única definición sustantiva del ser humano. Por tratarse justamente de un lenguaje con una carga normativa fuerte, la tarea de discernir quién puede legítimamente 
nombrar al sujeto que hace de núcleo de los derechos humanos -si es que se debe hacer- trasladándole en esta operación el particular modelo de sociedad y de subjetividad que ellos proponen es uno de los dilemas morales más punzantes a los que se han enfrentado a lo largo de su recorrido histórico y de su trayectoria fuera del recinto occidental donde nacieron (Mignolo, 2009). Resultado directo de esta problemática es la crítica frecuente al uso que se ha hecho de este discurso con objetivos colonialistas, paternalistas o de expansión imperialista (Douzinas, 2013).

Lo anterior es especialmente relevante si tenemos en cuenta que, históricamente, el lenguaje de los derechos humanos se ha activado allí donde se considera que las personas viven situaciones en las que sus atributos básicos son desconocidos y los derechos que se derivan de ellos les son negados. Reconocer en el sufrimiento de los demás, cuando es el resultado de una situación de desventaja social o política, una lesión a su dignidad humana y una demanda implícita de reparación del agravio, es parte de la promesa de justicia que los derechos humanos entrañan. En este sentido es que Lynn Hunt, quien ha estudiado la construcción moderna del sentimiento de empatía como fundamento de ese ethos, entiende que "los derechos humanos [...] descansan sobre una determinada disposición hacia los demás, sobre un conjunto de convicciones acerca de cómo son las personas y cómo distinguen el bien del mal en el mundo secular" (Hunt, 2009: 26).

Lo anterior implica que la cultura no puede quedar simplemente como un territorio sobre el cual los derechos humanos actúan por reflejo o por derivación, desde un estatuto legal considerado como su verdadera naturaleza. Ella es, por el contrario, el espacio donde la lucha por el reconocimiento (Honneth, 1997) que ellos formulan se sostiene en lógicas complejas, históricamente situadas, que incluyen procesos de visibilización, promoción, reconocimiento y defensa de distintos reclamos y de los individuos que los 
realizan, y de debate, negociación y reformulación públicos de los mismos por parte de diferentes comunidades, con mayor o menor potencial para hacerse escuchar y dejar escuchar a otros, para invocar y extender, o cuestionar y rechazar, los derechos y atributos en cuestión. En el corazón de esta lucha se encuentra la desigual distribución de los recursos culturales, sociales y políticos que pautan los escenarios en que determinados sujetos pueden (des) conocerse e interactuar (Butler, 2006a).

El aspecto discursivo de este fenómeno es ineludible, en tanto las demandas formuladas en el lenguaje de los derechos humanos exigen una voz que las articule públicamente y que sea capaz de interpelar a la comunidad para convocarla en su apoyo, y en tanto la voluntad de escuchar o no esa voz, de dialogar con ella y de responderle, supone la validación o desestimación colectiva de la identidad de los sujetos que sostienen esas demandas. A través de los múltiples y complejos mecanismos institucionales y discursivos involucrados en la legitimación de identidades públicas y de lealtades políticas y sociales, algunos grupos logran construirse y/o ser construidos como ciudadanos, como seres humanos o, más radicalmente, como "vidas que cuentan como vidas" (Butler, 2006b: 46), mientras otros resultan negados como portadores de una verdadera humanidad que merezca la pena ser protegida. En numerosas ocasiones, por otro lado, grupos que ya se han constituido como sujetos de derechos humanos, deben validar una y otra vez ante la arena pública esta condición cuando se incurre en el desconocimiento de sus derechos fundamentales. En este sentido, los derechos humanos se activan con nuevos actores emergiendo al espacio político, pero se reactivan cada vez que algunos sujetos ya reconocidos deben volver a reivindicar sus prerrogativas.

Ahora bien, la capacidad de los derechos humanos de erigirse en un potente mecanismo configurador del reconocimiento intersubjetivo no puede entenderse desligada de esa otra por la cual 
institucionalizan las relaciones del sujeto con el poder, "contra" el poder. Si, como afirma Bobbio, "el iusnaturalismo ha tenido la fundamental y permanente función de poner límites al poder del Estado" (1991: 42), la idea de unos atributos inalienables que no se pueden desconocer o violar porque son inherentes a la propia condición humana ha funcionado como una formidable justificación de la denuncia legítima que el individuo puede esgrimir contra un poder que incurre en un ejercicio ilegítimo, lesivo o directamente abusivo. El principio según el cual, idealmente, cualquier persona puede recurrir a las instituciones propias del poder político y jurídico para hacer valer sus derechos y obligar al Estado a garantizar ciertas condiciones que le permitan llevar una vida digna, libre y en igualdad con los demás, han convertido al discurso de los derechos humanos en una de las dimensiones definitorias de la constitución de un poder democrático en las sociedades modernas.

La trayectoria de esta noción de unos atributos "naturales", que se traducen en derechos específicos en el orden socio-político, es muy anterior a su codificación durante la Ilustración, y está vinculada directamente a la convicción de la sacralidad de la vida humana, de clara matriz religiosa (Tierney, 2001). Pero es recién a partir de su constitucionalización en los Estados nacionales que reflejan la voluntad del poder de generar mecanismos de auto-limitación internos y el compromiso específico a comportarse dentro de esos límites ante cualquier individuo, sin distinción de ninguna otra clase. La distancia entre esta proclamación ideal y su instrumentación real es por supuesto enorme, y sigue teniendo consecuencias dramáticas. Pero las distintas generaciones de derechos, y los diferentes instrumentos y organismos nacionales, regionales y supranacionales que se han ido creando o perfeccionado para actuar como instancias efectivas de reclamación y reparación, dan cuenta de hasta qué punto la legitimidad democrática y los derechos humanos se han identificado entre sí. El resultado es que se han 
convertido en uno de los lenguajes políticamente más prestigiosos a los que el individuo puede recurrir, dentro de los marcos institucionales, para enfrentar al poder, denunciarlo y hacerlo cumplir.

\section{El discurso literario y los derechos humanos}

Abordar los derechos humanos como una modalidad del reclamo de justicia, cuyo centro es el individuo o grupo vulnerado por situaciones de desventaja social, nos permitió entender hasta qué punto distintas modalidades de la literatura latinoamericana se identificaron con ese impulso de hacer visibles y defender a sujetos en condiciones de desigualdad e inequidad. La idea, además, de que la doble interpelación que los derechos humanos plantean no puede más que dirimirse en el espacio público, donde las diferentes identidades y reclamos se miden en su capacidad de hacerse escuchar y respetar, de conquistar y hacer cumplir sus demandas de derechos, hizo posible comprender las numerosas ocasiones en que el discurso literario trabajó para traer al espacio colectivo relatos con las palabras, las experiencias y las necesidades de grupos silenciados e invisibilizados, articulando una dura denuncia a las configuraciones del poder político y exigiendo su transformación en favor de los más vulnerables. La implicación de la literatura con la ética de los derechos humanos es notoria analizada desde esta perspectiva, en especial porque la orientación social y política de la misma es quizás uno de sus rasgos más persistentes y característicos. En América Latina, el discurso literario se constituyó muy frecuentemente en un espacio de reflexión sobre el poder, la sociedad y las posibilidades y formas de la justicia. Este "mesianismo irrenunciable" -que Mabel Moraña atribuye al intelectual latinoamericano, pero que es también un elemento distintivo de la literatura (Moraña, 1998) - está íntimamente asociado al descontento generado por una persistente condición periférica, un pasado co- 
lonial marcado por la fractura epistemológica de la conquista y sus nefastas consecuencias, y un extendido malestar ante las fortísimas y resistentes tensiones raciales, culturales y sociales. En ese contexto, una parte nada desdeñable de la literatura latinoamericana utilizó mecanismos de empoderamiento similares a los del discurso de los derechos humanos, al insistir en la dignificación de la vida humana y al postular modelos posibles de convivencia y de poder más justos e integradores.

Ello no quiere decir que no hayan existido manifestaciones literarias que abogaron por el mantenimiento del status quo, que defendieron la exclusión de lo que hoy llamaríamos sujetos subalternos y, en especial, el repudio a determinados grupos cultural o étnicamente marcados, ayudando así a delimitar las fronteras rígidas y excluyentes de la comunidad nacional. Supone sí que, a la par de esas expresiones, se desarrolló una literatura con una intencionalidad y un potencial enormemente crítico con las condiciones sociales y políticas de la realidad latinoamericana-desde Bartolomé de las Casas hasta las actuales narrativas en torno a la memoria, pasando por las novelas del dictador, el indigenismo, el negrismo, la poesía social, la canción de protesta o las cada vez más prestigiosas formas del hip-hop- que construyó relatos sólidos acerca del papel de la autoridad y el ejercicio legítimo del poder, y que buscó resignificar la presencia de esos sujetos marginados en el espacio político y afectivo de la nación, intentando realinear las lealtades comunitarias hacia sociedades más inclusivas. Aun cuando muchos de esos textos manejaron recursos ambiguos, y a veces hasta contradictorios con esa orientación ética, esta línea de la literatura latinoamericana realizó la tarea nada menor de trasladar hacia la esfera de los debates públicos la representación de los sujetos vulnerados, dando credibilidad a sus voces, hablando de su humanidad castigada, y revistiendo de cuerpo y carne sus sufrimientos y la violencia de la que fueron objeto, en un intento por 
interpelar a ese otro "distinto/semejante" - a veces nacional y otras continental- capaz de comprometerse y responder a esas imágenes. Esta tarea fue especialmente importante, sobre todo, porque detrás de la denuncia que estos textos realizan de la violencia estatal y social, de la explotación económica y de la fragmentación étnica y cultural, lo que allí se pone en juego es precisamente lo que hace al núcleo ético de los derechos humanos: las definiciones posibles de lo que es ser humano, los límites deseables y admisibles con lo no-humano y las consecuencias colectivas de esa definición (Butler, 2006a).

Estas manifestaciones literarias comparten así las características de lo que en las últimas dos décadas ha venido siendo objeto de una poderosa teorización, tanto en el ámbito latinoamericano como anglosajón. Se trata de un nuevo campo de estudio centrado en las respuestas, individuales y colectivas, a violaciones masivas de los derechos humanos en situaciones de violencia extrema: acciones bélicas contra la población civil, masacres y genocidios, reclusión ilegal y tortura, persecución política-ideológica, desapariciones clandestinas, desplazamientos masivos y exilio forzoso. Lo que en el ámbito de habla inglesa se ha identificado como un subgénero específico -las "human rights fictions" (Dawes, 2007; Slaughter, 2007) o, en un sentido más amplio, el "storytelling" (Schaffer y Smith, 2004) - en el contexto latinoamericano ha significado un aluvión de producción en torno a lo que se podrían llamar las narrativas del trauma o de la memoria -relatos autobiográficos, cartas, testimonios, ficciones testimoniales, memorias individuales y colectivas y ficciones propiamente dichas que recrean situaciones históricas de violencia- asociadas a crímenes de lesa humanidad de los últimos cincuenta años, a los procesos posteriores de búsqueda de la verdad y reclamación de justicia, y a los intentos de recuperación de las subjetividades fragmentadas por esas experiencias y marcadas por la (im)posibilidad de recordarlas, hablarlas y trans- 
mitirlas. En conjunto, estos abordajes exploran una riquísima y muy compleja interrelación de textos escritos con documentales, exposiciones y proyectos fotográficos y audiovisuales, instalaciones artísticas, lugares de conmemoración y de espacios utilizados en las actividades de detención, tortura y desaparición, expresiones urbanas de arte callejero como murales y grafitis, muestras de teatro comunitario o actividades performativas, marchas, manifestaciones o vigilias.

Ello ha dado lugar, por un lado, a un intenso trabajo de reflexión acerca de los esfuerzos de ciertos grupos por luchar contra la impunidad y reapropiarse de un pasado desfigurado y trastocado por retóricas que eximen al Estado de su responsabilidad, y que desvirtúan y minimizan la gravedad de las violaciones cometidas, indagando en esa voluntad de afrontar y asumir los hechos y sus secuelas, no sólo por parte de las víctimas sino también de la sociedad que ha sido lesionada por esos acontecimientos (Forcinito, 2014). Al enfocar los derechos humanos, por otro lado, como una de las matrices del pensamiento moderno, éstos se revelan como un campo de tensiones que promueve ciertas lógicas de poder y de justicia mientras suprime otras, y que afianza determinadas maneras de auto/re-conocimiento social y político al tiempo que oblitera formas alternativas de construcción inter-subjetiva. De este modo, se convierten en una "heremeneutical key to an analysis of the interconnections of power and identity and the challenges that a plural society presents to the logic of the nation-state's power" (Forcinito y Ordóñez, 2009: 3). En ese sentido, funcionan "as a cultural text where the ethical and unethical relations towards others are represented" (Forcinito y Ordóñez, 2009: 13). Entender los derechos humanos de esta manera es, precisamente, lo que permite pensar ese diálogo con el discurso literario como una característica que se extiende más allá de la historia reciente del continente, para abarcar periodos de tiempo más prolongados 
y problemáticas distintas. Lo que emerge, entonces, es el empuje democratizador que la literatura latinoamericana ha tenido, con notoria evidencia desde finales del siglo XIX, al asumir la representación de ciertos sujetos como seres humanos dignos, portadores de derechos, titulares de ciudadanía, y merecedores de reconocimiento social y cultural.

Para mostrar de qué manera esta segunda mirada más abarcadora puede resultar productiva, me gustaría proponer -a través del análisis ejemplificativo de dos novelas, Chambacú corral de negros, del colombiano Manuel Zapata Olivella, publicada en 1963, y Redoble por Rancas, de Manuel Scorza, publicada en 1970 y primera de las cinco obras que componen "La guerra silenciosa", un friso de la problemática indígena en Perú- la existencia de una modalidad de argumentación que, a mi juicio, es la que sostiene la capacidad de toda esta literatura de articular los fundamentos éticos de los derechos humanos. Se trata de la construcción retórica de tres efectos de lectura, indisociables entre sí en el discurso narrativo: un efecto "persuasivo", abocado principalmente a convencer y movilizar afectivamente, un efecto de "denuncia", por el cual los agravios son construidos como actos indefendibles de un poder ejercido ilegal y/o ilegítimamente, y uno "potestativo" que, a la inversa, busca investir a los sujetos agraviados con la legitimidad que les garantiza el deber de reclamar el derecho a tener derechos. En conjunto, estas tres estrategias estructuran la representación de los sujetos cuyos derechos fundamentales han sido violados, y sirven para "argumentar" públicamente en su favor.

En cuanto a las novelas elegidas, Chambacú, corral de negros y Redoble por Rancas pertenecen, en efecto, a un momento histórico distinto al delimitado habitualmente por los estudios en literatura y derechos humanos. Se trata de textos que se enmarcan en una etapa de drásticos cuestionamientos a las estrechas definiciones liberales de la ciudadanía, y en la cual un sector importante de los 
intelectuales de clase media pretendía extender el reconocimiento de los derechos básicos a grupos históricamente marginados. Desde el punto de vista literario se inscriben, sin embargo, en un tipo de escritura realista que, hoy en día, es vista como un ejercicio de apropiación de la voz del otro. Suponen, por tanto, un modelo de creación literaria problemático en su capacidad de re-presentar a los sujetos subalternos, en tanto la voz de éstos aparece aquí captada, cuando no "capturada", por la de un narrador exterior $y$, en parte, ajeno a las comunidades que representan las novelas (Rama, 1989). Desde esta especificidad histórica y literaria, ellas me permitirán mostrar cómo funcionan los tres efectos de lectura mencionados y cómo, a través de ellos, estos textos forman parte -a pesar de todas sus contradicciones internas- de esa prolongada modalidad literaria que incorporó los principios de los derechos humanos.

\section{Construyendo sujetos de derechos humanos en la literatura}

Hacer visible el sufrimiento inmerecido, y lograr que ese mismo sufrimiento sea ya una exigencia de reparación, son tareas centrales al funcionamiento de los derechos humanos y al propósito de rehumanización que llevan adelante estos textos literarios. Ninguna de las dos novelas se puede entender cabalmente si el lector no es capaz de sentir que los negros y los indígenas sobre los que está leyendo padecen un dolor que no merece ningún ser humano, precisamente porque la situación que experimentan los desfigura y los enajena en tanto se revela como inhumana. Los sujetos colectivos de estos relatos surgen así ante el lector como seres vulnerables y vulnerados. A partir de esta vulnerabilidad, los relatos buscarán tender un puente entre los personajes y el lector que restaure su condición de semejantes, por encima y a pesar de todas sus posi- 
bles diferencias. Ello es así en especial en estos dos casos, porque el sufrimiento es aquí la consecuencia directa de la posesión de una marca que resulta intolerable e inasimilable para la comunidad nacional. Las experiencias de humillación, privación y exclusión que van a relatar estos textos se fundan en la condena de una identidad étnica y cultural que alimenta la percepción de la extrańeza y ajenidad de los protagonistas y convierte en problemática su condición de ciudadanos.

El 'corral' de Chambacú, es un hacinamiento de casuchas hechas con "desperdicios de la ciudad [...] retazos de fique, tablas y lonas envejecidas. El techo de ramazones, palma de coco y oxidadas hojas de zinc" (Zapata Olivella, 1990: 56), delimitado por manglares y cańos de agua "donde los zopilotes se disputaban los cadáveres de gatos y perros ahogados” (45). Estos caños, que atraviesan también toda la isla y donde se acumula la basura del barrio, funcionan como la única precaria barrera defensiva que los negros pueden erigir contra las amenazas constantes del ejército y las amenazas de desalojo pero, sobre todo, simbolizan el estado de postración casi parasitario en el que están obligados a permanecer. Para sobrevivir, se alimentan de los peces que logran atrapar o se hunden en el agua fangosa para conseguir almejas podridas. Toda la existencia física en la isla aparece aludida por estas referencias a lo malsano, a la corrupción material y a una atmósfera nauseabunda y de miasma. Los excrementos, los desperdicios mezclados, los mosquitos y jejenes que acosan a los personajes, los perros sarnosos, las ratas y la humedad que hace multiplicar larvas y parásitos, son las imágenes que describen la pobreza y su manifestación más radical, el hambre.

Sobre estos dos ejes, la degradación material y la violencia directa y constante por parte del ejército, en los que el centro narrativo es el cuerpo vejado y sufriente, la ficción construye el drama humano que surge a raíz de ese estado de vulnerabilidad extrema. 
$\mathrm{Y}$ es esta otra narrativa sentimental, en realidad, la que absorbe a la anterior y encuadra en los textos el sentido que debe dársele a esa situación de pura existencia física maltratada. Como mecanismo de persuasión, las novelas no sólo identifican los síntomas tangibles del despojo, sino que buscan fundamentalmente revelar la dimensión social y humana que éste produce. Vemos entonces el gesto desesperado de reconocimiento de la Cotena con su hijo Máximo, el 'cabecilla' del barrio, al que abraza, besa y lame porque el tiempo de cárcel y tortura "se lo devolvió irreconocible [...] Se lo escurrieron hasta dejarlo en puros pellejos" (Zapata Olivella, 1990: 157). Vemos a Clotilde, hermana de Máximo, golpear en la boca a su propio hijo cuando pide ir a la guerra porque imagina que ser soldado es poder caminar con polainas sin mojarse los pies. Pero vemos asimismo a las prostitutas del barrio, mellizas sin padre y sin nombre propio, amancebadas con el padrastro y embarazadas por él, trabajando en su cantina, sufriendo la ausencia de los hombres de la isla. La novela despliega así todo el abanico de luchas y mezquindades que nacen del abandono, del desprecio colectivo y del aislamiento.

En Redoble por Rancas no son los hombres lo que el poder arrebata sino la tierra, exponiendo a la pobreza y al desamparo a toda la comunidad. En Rancas, una de esas aldeas de los Andes "solo visibles en las cartas militares de los destacamentos que las arrasaron" (Scorza, 2002: 149) -como se dice en la Noticia que antecede el texto- la falta de alimento hostiga a la comunidad a causa de la pérdida de terrenos fértiles, de los cuales se apropia el Juez Montenegro, como lo hace la escasez de agua y la mortandad de animales que ya no tienen dónde pastar debido al vertiginoso avance del cerco que seńala las propiedades de la Cerro de Pasco Corporation. También aquí, pues, la violencia se ensaña con la vida física de los personajes pero, sobre ese hecho, se construye igualmente el drama de la comunidad indígena amenazada con su borramiento. Las dos 
historias entrelazadas de la ficción van desenvolviendo momentos de impotencia y resentimiento compartidos. Los ojos "que quemaban” del hijo de Héctor Chacón, quien la víspera del asesinato de Montenegro le dice "acaba con los hacendados, papá. Yo te ayudaré. Para que no sospechen nada yo llevaré mañana las armas bajo mi poncho" (Scorza, 2002: 187), sin saber que está reviviendo los sentimientos del propio Héctor nińo, que mira los ojos de su padre humillado por el Juez. Momentos íntimos de dolor ante la pérdida, como el de la comunera Silveria Tufina ante su rebaño de ovejas degolladas - "señorita, duérmete- sollozó la vieja acariciando la cabeza de una oveja moribunda” (Scorza, 2002: 280) o la desesperada carrera de Fortunato a lo largo, literalmente, de todo el texto, para alcanzar la pampa y avisar de la llegada del ejército: "cada roca, cada charco, cada mata, eran inolvidables para él. [...] En esa estepa maldecida por los forasteros [...] él, Fortunato, había nacido, crecido, trabajado, maravillado, conquistado y amado. ¿También moriría?” (Scorza, 2002: 161).

Si pensamos, entonces, que las obras visibilizan el sufrimiento de los sectores vulnerables como parte de un efecto de persuasión, podemos avanzar algunas consideraciones. En primer lugar, la construcción literaria del sufrimiento ajeno logra parte de su efecto a la vez apoyándose en esa ajenidad y tratando de abolirla. Como se trata de narrativas heterogéneas en las que el público lector es en principio distinto al sujeto representado (Cornejo Polar, 1980), y como estamos además ante relatos que definen a los sujetos colectivos como miembros marginados de una comunidad nacional tensionada por diferencias raciales y culturales, los textos buscan respetar y promover la identidad particular de los protagonistas al tiempo que delimitan un terreno común en el que su humanidad amenazada valga más que la particularidad que los diferencia. La descripción del sufrimiento cumple con ese objetivo al apuntar a la comprensión del lector de que ninguna marca identitaria puede 
justificar el trato que estos grupos reciben y, en consecuencia, a su capacidad de sentir compasión e indignación por/con ellos. En ese sentido, la estrategia de promover la identificación emocional con experiencias tan básicas como el hambre, la tortura o la pérdida, y con sentimientos como la impotencia o la desesperación (Laqueur, 1989) se convierte en una vía para redimensionar el significado y el lugar que se le otorgan a esas identidades marginadas. Esta "empatía imaginada” (Hunt, 2009: 31) debería, a su vez, ayudar a redefinir el mapa afectivo por el cual se delimitan las lealtades dentro de la propia comunidad nacional de iguales. La tarea de persuadir combina, por tanto, una reivindicación de los negros e indígenas, que intenta no desprestigiar ni 'suavizar' esta especificidad, con un ejercicio de interpelación emotiva que pueda movilizar la humanidad que estos sujetos y la comunidad de lectores tienen en común.

Desde esta perspectiva, en segundo lugar, los textos manejan una categorización triple de sus protagonistas. Como portadores de una identidad considerada deficiente o peligrosa, han sido excluidos de la plena ciudadanía y ello, como vimos, termina vulnerando su misma condición de seres humanos. Cada una de estas categorías se pliega entonces sobre las otras y las refuerza, habilitándose y justificándose mutuamente. A partir del primer reconocimiento básico de la humanidad de estos grupos, las novelas apuestan a una especie de re-ciudadanización afectiva, una extensión del reconocimiento social y político imprescindible para reivindicar su dignidad, reclamar sus derechos y restituirlos como miembros plenos de la nación, pero ya no en base al aniquilamiento o al borramiento de su singularidad, sino a través de su aceptación e incorporación. Como en el caso de los derechos humanos, narrar el dolor del otro es parte central de una apuesta afectiva, ética y política que se asienta sobre los mecanismos de empatía, reconocimiento y reciprocidad. 
Este primer efecto de persuasión depende estrechamente, sin embargo, de mostrar ese padecimiento inmerecido como consecuencia directa del ejercicio ilegítimo de la autoridad. Si, en palabras de Hernán Vidal, "power is severely weakened if its brutal realism remains exposed for long” (Vidal, 2009: 37), el efecto de denuncia se encarga precisamente de exponer la realidad del poder. Y lo hace a través de un profundo cuestionamiento del orden legal e institucional en el que las acciones del Estado, sus alianzas con los capitales y organismos internacionales y, principalmente, los operativos de su instrumento más conspicuo de violencia, el ejército, diseñan un espacio en el cual el poder no sólo se ha vuelto completamente arbitrario, sino que ha dejado de reconocer a la vida humana como límite infranqueable. En un primer sentido, los textos construyen esta percepción de la ilegitimidad del poder a través de personajes que tergiversan el orden público que representan -jueces, presidentes, militares, prefectos, inspectores- para hacerlo coincidir con intereses privados o para reforzar un estado de cosas en el que algunos se benefician de las riquezas y los privilegios mientras se expone a otros a la privación, la enfermedad o la muerte. La perversión de la autoridad asume la forma de círculos concéntricos, conectados a través de un mismo ejercicio de violencia, en la que participan todas las instancias de poder, creando una sensación de opresión ubicua y sin fisuras. Esta desviación del bien general, al interior del espacio nacional, que resulta en la corrupción de la promesa igualitaria de la ley, aparece entonces ligada a un orden internacional en el que la impunidad se extiende para abarcar a empresas e intereses extranjeros que se suman así a la explotación de las comunidades protagonistas. En una segunda instancia, sin embargo, esa primera denuncia refiere siempre al problema de la disputa por la tierra. Tierra que los sujetos colectivos habitan y no pueden poseer y tierra de la nación que no los acoge, tierra que trabajan y se les quita y tierra por la que deciden morir. 
La tierra es, pues, lugar material donde los protagonistas viven y trabajan, pero también espacio alegórico a partir del cual se dramatiza la pertenencia conflictiva de estos grupos al Estado-nación. Esta violencia, y la que se ejerce sobre el cuerpo, aparecen entonces como superpuestas, implicándose mutuamente en la denuncia de las distintas formas de exclusión y aniquilamiento.

En Chambacú, corral de negros la idea de que el lugar que los negros habitan es 'usurpado' a la ciudad aparece constantemente y mantiene vivas las amenazas de desalojo. Pero un episodio particular revela las aristas más profundas de ese conflicto. Atilio es uno de los hombres que desaparece después de la redada del ejército. Con él, su madre pierde al único hijo que puede mantenerla y comienza un proceso de locura que culmina cuando confunde la visita del Cuerpo de Paz con un homenaje a su hijo caído en la guerra. Al no ver el ataúd entre la multitud, desesperadamente demanda una sola respuesta: “¡Mi hijo! ¿¿Dónde lo dejaron?”, “¿Dónde enterraron a mi Atilio?" (Zapata Olivella, 1990: 225-226). El resultado es que un soldado intenta hacerla callar y le aplasta el rostro con su bota hasta matarla. A través de esa doble ausencia -la del cuerpo de Atilio y la de la posibilidad de un entierro- la novela condensa todas las formas de no-pertenencia que sufre la comunidad negra. La ausencia de un cuerpo que enterrar evoca tanto la negación del derecho a una genealogía propia, a una historia particular de la comunidad negra que le permita tener sus propios muertos y recordarlos, como la negación de la metáfora de la patria, madre que acoge a todos sus hijos. Si la madre de Atilio se queda sin hijo y sin tumba es porque se rechaza no sólo la presencia negra en la nación colombiana -el cuerpo que falta- con la continuidad histórica que implica a través de padres e hijos y el recuerdo que se teje entre ellos, sino un relato nacional que dé cuenta de esa continuidad y la integre al presente -la tumba que lo recuerde-. Que el territorio físico de la nación no pueda acoger el cuerpo sin 
vida de un negro implica su exclusión de la comunidad de vivos y muertos que la conforman y supone, por tanto, la no participación en la memoria colectiva por la cual esa nación se extiende hacia el pasado y el futuro. La negación de una tierra 'propia' alude, pues, a una triple privación de derechos: el de un lugar digno donde vivir-Chambacú está hecha de los desechos de la ciudad-, un lugar donde morir, y el derecho a tener una memoria propia y a ser parte de la colectiva. Que, finalmente, no se sepa ni cómo ni dónde murió Atilio, y que su madre muera preguntando por él, resumen a la perfección de qué forma se ejerce una violencia tan radical que puede quitar la vida, apropiarse de los cuerpos y quedarse con las respuestas sobre esos actos.

En Redoble por Rancas, lo que exacerba la idea de una apropiación ilegítima de tierras y ganados es el hecho de que no hay intento alguno por disfrazar o disimular los intereses personales que la motivan. Cuando Chacón le reclama al Juez la retención de todos sus caballos, la respuesta del mayordomo no tiene dobleces: "Tú eres muy alzado, Chacón. El doctor quiere que aprendas" (Scorza, 2002: 262). Más tarde, cuando los animales del propio doctor destrozan el papal de Héctor, la esposa de Montenegro le espeta sin más: “¡Me alegro que mis animales acaben con tu chacra! Tú eres un cholo insolente, un indio de mierda. Como peor te portes, peor te irá" (266). La misma lógica se utiliza con el avance del Cerco. No hay explicaciones ni retrocesos, sólo violencia pura sobre los hombres y los animales que se le oponen. La respuesta a las primeras rondas nocturnas para hacer pastar las ovejas en tierras cercadas no tiene ambigüedad: "Se levantaron alarmados mientras una pelota rodaba hasta sus pies. Se acercaron: era la cabeza de Mardoqueo Silvestre" (255).

Pero el verdadero tamaño de la injusticia se mide a través de la figura del desquiciamiento del orden natural. Si la privación que causa Montenegro es aún manejable en la posibilidad de eli- 
minarlo, la magnitud del mal que trae consigo el Cerco es, por el contrario, inimaginable e ingobernable. Por ello, los animales, los pájaros, las plantas transmiten el desorden total del mundo que se avecina: "olvidando enemistades, los cernícalos volaban en pareja con los gorriones” (Scorza, 2002: 159), “en Junín, una vaca parió un chancho de nueve patas" ( 218). En su expresión más extrema, los seres humanos desacatan las leyes naturales: "Ahora sí [...] el padre se comerá al hijo; el hijo se comerá a la madre" ( 233). La inversión del mundo señala ese límite en que la privación de la tierra se convierte en un proceso de deshumanización. Lo que estos poderes le quitan a la comunidad no es sólo un sostén material, sino una parte constitutiva de la red de referencias afectivas y de pertenencia que dicen quién es ella. Sin la tierra, algo en su identidad humana termina también desquiciado.

Vistos en conjunto, por tanto, la capacidad de denuncia de estos relatos liga tres aspectos fundamentales de la relación que se establece entre los protagonistas y el poder: la ausencia de un límite -físico y moral- que este último sea capaz de reconocer como frontera infranqueable de acción, la consiguiente incapacidad de los sujetos colectivos para detener el abuso, invocando para ello una humanidad desconocida en su dignidad y vulnerada en sus derechos y, en consecuencia, la absoluta ilegitimidad de una autoridad que se ejerce en su plena desnudez, como pura fuerza. En virtud de la denuncia, pues, los textos amplían el vínculo de empatía que pretende generar la narración del sufrimiento de las comunidades, con la representación del entramado de relaciones jerárquicas asimétricas por las cuales éstas son sometidas a poderes que actúan injustamente. Los relatos deben hacer congeniar en la lectura, por tanto, la imagen de un mundo narrativo construido en base a antagonismos de clase, de género y etnia, de cultura y memorias históricas, con un efecto contrario que potencie la construcción de solidaridades interraciales, interculturales e interclasistas. 
Pero, además, no se detienen allí. Porque esta retórica queda nuevamente redimensionada por el tercer efecto de lectura, el gesto potestativo mediante el cual se confiere a las comunidades la legitimidad para responder al agravio, protestar, exigir y, en última instancia, luchar con su propia vida. Lo que, desde las perspectivas anteriores, es contado como una historia de sufrimiento y deshumanización, es también la trayectoria que lleva a los protagonistas a reconocer su propia dignidad, a exigir en base a ella sus derechos e, incluso, a decidir morir por ellos. Más aún, a través de esta estrategia los textos reelaboran dos elementos centrales del paradigma de los derechos humanos: que la protección de la vida humana es la fuente última y el límite inapelable del poder y que, en situaciones de opresión, los seres humanos tienen siempre el derecho a resistir la injusticia. En este sentido, el efecto potestativo resulta imprescindible para unos textos que tienen el propósito de llevar la experiencia de ciertos sujetos silenciados al espacio público colectivo. Gracias a él, el abuso y el dolor que los protagonistas deben soportar adquiere no el carácter de un lamento, sino el de un empoderamiento para la acción que los postula como sujetos activos, capaces de articular y defender sus propias demandas. Gracias a él también, el desafío y el enfrentamiento armado al poder son reivindicados como expresiones del antiguo derecho de resistencia, y no como una forma ilegítima de insubordinación o subversión. En los dos casos, finalmente, la decisión de luchar con el propio cuerpo, como última y única arma, aúna en un mismo gesto la máxima denuncia y el mayor sacrificio posibles, en tanto muestra al poder desnudo de cualquier ficción de autoridad, y a los sujetos en disposición de salvaguardar sus derechos, incluso con la vida.

Las dos novelas van mostrando las distintas formas que tienen los protagonistas de protestar ante la injusticia pero, en ambas también, existe un momento que funciona como un límite: quien surge del otro lado no es sólo la vida sufriente y maltratada, ni 
tampoco el ser indefenso y acosado, sino un sujeto sometido a una nueva vejación, pero dispuesto a pelear. En Redoble por Rancas la toma de conciencia colectiva de que es imperioso luchar decanta al final, cuando el ejército viene a represaliar a la comunidad. Lo que hace que Fortunato llame al enfrentamiento, sin embargo, es un súbito 'descubrimiento'. Involuntariamente asocia el desconcierto de los ranqueños ante la noticia con las moscas atontadas por la luz: "-No somos moscas - dijo en voz alta". Los gritos de Teodoro Santiago llamando a los comuneros a arrodillarse y a arrepentirse de sus pecados termina de convencerlo: “-¡Silencio, carajo! [...] No es hora de gritar, sino de pelear. Hoy nos jugamos el todo por el todo. ¡Ármense con palos, con piedras, con lo que sea! ¡El todo por el todo! ¿Oyen?” (Scorza, 2002: 370). Lo que sigue es la matanza de los comuneros y el incendio de la aldea pero, durante el enfrentamiento, se produce un segundo hecho importante: la comunidad espontáneamente reclama la autoridad sobre los símbolos patrios. Parado frente a un imperturbable alférez que va descontando el tiempo que tienen para desalojar, Fortunato le grita: "Ése no es el uniforme de la patria -se agarró la chaqueta- Éstas hilachas son el verdadero uniforme, estos trapos...!" (372). Cuando lo matan a quemarropa, es el Personero Rivera quien trae la bandera y llama a cantar el himno: "Finalmente comenzamos: 'Somos libres, seámoslo siempre'. Yo pensaba 'van a cuadrarse y saludar'. Pero el alférez se calentó: '¿Por qué cantan el himno, imbéciles?' ‘'Suelta eso!', me ordenó. Pero no solté la bandera. La bandera no se suelta” (374). Gran parte de lo que sucede después está contado por los muertos, quienes se dan información unos a otros. Por ellos nos enteramos de la masacre de la comunidad, pero también de la respuesta enfurecida de la gente y de que hasta los nińos intentaron defenderla.

En Chambacú, corral de negros es una última pérdida, la de la madre de Atilio, lo que marca el límite de lo que el barrio está 
dispuesto a tolerar. Frente al cuerpo ausente de Atilio, sin tumba y sin respuestas sobre su muerte, el ataúd de la madre asesinada se convierte en la representación de todos los reclamos:

Pasearían el cadáver por la ciudad. Un desfile de haraposos en busca de una sepultura. Mostrarían su miseria. La abandonada por siglos en el corral olvidado. El puente sería un camino para llegar a los portalones de los que se decían adorar a Pedro Claver. Debían saber que Chambacú necesitaba mucho más que banderines y limosnas (Zapata Olivella, 1990: 229).

Todo aquí se vuelve simbólico: el corral, los harapos, la búsqueda de la sepultura. Pero sobre todo el cruce del puente: el desafío a los límites físicos, culturales y raciales impuestos sobre ellos por la ciudad y, con ese traspaso, la explicitación de las ansiedades y temores que genera la mezcla y el contacto. Máximo ya se lo había explicado así a Inge, su cuñada extranjera: "Temen que un día crucemos el puente y la ola de tugurios inunde la ciudad. Por eso, para nosotros no hay calles, alcantarillados, escuelas ni higiene. Pretenden ahogarnos en la miseria" (Zapata Olivella, 1990: 199). La procesión termina con la muerte de Máximo y la aparente vuelta de los adultos a la indiferencia y el conformismo. Hasta que Dominguito le recuerda en voz baja a su tía que los están esperando en la escuela, para usar las mismas semillas de aguacate con las que su tío Máximo hacía las pintadas de denuncia.

A través, pues, de la pérdida total de derechos, y del sufrimiento que ello genera, el camino que los protagonistas transitan aparece narrado como un proceso por el cual descubren que, cuando lo único que queda por proteger es la vida, la resistencia al abuso no es sólo un acto instintivo o indignado de defensa propia, es también en sí mismo el símbolo de la recuperación de la dignidad que les ha sido negada. En su dimensión humana, el reencuentro con esa dignidad en el momento de mayor vejación y violencia es 
el descubrimiento del valor propio, y la manifestación de aquello que el poder no puede de ningún modo quitar sin impunidad, aun cuando, en las novelas, los personajes pierdan la vida. En su dimensión política, funciona como recuperación simbólica del lugar que los protagonistas no tienen en la comunidad nacional. El derecho a la desobediencia legítima a la autoridad, que se activa cuando la comunidad se ve gravemente amenazada por un poder que ha dejado de protegerla, y que se ejerce en defensa de los valores comunes que deberían convocarla, forma parte de una larguísima tradición de derecho natural que, en el proceso de constitucionalización de los derechos humanos, fue quedando progresivamente desplazada en favor de la institucionalización pacífica y gradual del cambio político y social.

Los relatos retoman dicha tradición de pensamiento y la hacen actuar en un contexto de antagonismos en el que los protagonistas aparecen como los únicos portadores posibles de unos ideales que, siendo los que representan las aspiraciones auténticas de la nación como modelo de convivencia y organización del poder, son también los más ausentes de la misma. La apropiación de los símbolos patrios que se da al final de Redoble por Rancas funciona, de esta manera, como reflejo de lo que se está tratando de argumentar: los sujetos pueden alzarse en armas legítimamente porque la verdadera autoridad moral reside en ellos, y no en un Estado que ha escindido ética y política y que revierte por ende a la pura fuerza física. La atribución de este lugar privilegiado es un núcleo central en la producción de sentido, porque la validación pública de la imagen que intentan transmitir de los negros e indígenas depende de que ella funcione efectivamente con el valor potestativo que pretende tener. 


\section{Conclusión}

Se ha propuesto que es posible formular la existencia de una larga genealogía de textos de denuncia, ligados entre sí por una idéntica convergencia con la ética de los derechos humanos. Llegados a este punto, creo que se puede afirmar que en conjunto estos textos ayudaron a crear un relato común acerca de la justicia que ha sido de enorme importancia en América Latina. Trabajando sobre las imágenes del desconocimiento de la dignidad humana, esto es, sobre los efectos deshumanizantes de la exclusión social y la violencia física, y denunciando las asimetrías de poder en la sociedad y las violaciones cometidas por el Estado, los relatos ofrecieron a los imaginarios colectivos nociones precisas acerca del papel de la autoridad y las formas de la justicia social que aún hoy se mantienen vigentes. Considerado así, este discurso literario funcionó, efectivamente, como una práctica de derechos humanos, en tanto se propuso favorecer la construcción de nuevos sujetos de derechos, interviniendo en el ensanchamiento de la definición de 'lo humano' y redignificando la presencia viva, la cultura y las memorias históricas de comunidades marginadas. Desde esta misma perspectiva, los propios derechos humanos aparecen bajo una nueva luz, como artefactos culturales multifacéticos y heterogéneos capaces de 'encriptarse' en otros lenguajes, y de actuar en espacios y de formas que están en principio muy alejados de la ley. Como una ética de la convivencia y del poder, entonces, los derechos humanos encuentran formas de manifestarse en códigos culturales distintos a sí mismos que, a su vez, ponen al descubierto las contradicciones, las aporías y los límites de esa filosofía de unos derechos iguales para todos, sin distinción. 


\section{Bibliografía}

Bobbio, Norberto, 1991, El tiempo de los derechos, Editorial Sistema, Madrid.

Butler, Judith, 2006a, "Afterword. The Humanities in Human Rights: Critique, Language, Politics", PMLA, vol. 121, núm.5, pp. 1658-1661.

,2006b, Vidas precarias. El poder del duelo y la violencia, Paidós, Buenos Aires.

Cornejo Polar, Antonio, 1980, La novela indigenista, Lasontay, Lima.

Dawes, John, 2007, That the World May Know. Bearing Witness to Atrocity, Harvard University Press, Cambridge/Massachusetts/ London.

Douzinas, Costas, 2013, "The Paradoxes of Human Rights", Constellations, vol. 20, núm. 1, pp. 51-67.

Forcinito, Ana y Fernando Ordóńez, 2009, "Introduction.Human Rights and Latin American Cultural Studies", Hispanic Issues On Line, vol. 4, núm. 1, pp. 1-13.

Forcinito, Ana, 2014, "Introduction. Layers of Memory and the Discourse of Human Rights: Artistic and Testimonial Practices in Latin America and Iberia”, Hispanic Issues On Line, vol. 14, pp.1-17.

Honneth, Axel, 1997, La lucha por el reconocimiento. Por una gramática moral de los conflictos sociales, Crítica, Barcelona.

Laqueur, Thomas, 1989, "Bodies, Details and the Humanitarian Narratives", en Lynn Hunt (ed.), The New Cultural History, University of California Press, Berkeley/Los Ángeles, pp. 176204. 
Mignolo, Walter, 2009, "Who Speaks for the Human in Human Rights?”, Hispanic Issues On Line, vol. 5, núm. 1, pp. 7-24.

Moraña, Mabel, 1998, "El boom del subalterno", en Santiago Castro-Gómez y Eduardo Mendieta (comps.), Teorías sin disciplinas. Latinoamericanismo, poscolonialidad y globalización en debate, Miguel Ángel Porrúa, México, pp. 233-241.

Rama, Ángel, 1989, Transculturación narrativa en América Latina, Fundación Ángel Rama, Montevideo.

Remedi, Gustavo, 2009, "Skeletons in the closet? Approaching Human Rights through Culture", Hispanic Issues On Line, vol. 4, núm. 1, pp. 58-85.

Schaffer, Kay y Smith, Sidonie, 2004, Human Rights and Narrated Lives: the Ethics of Recognition, Palgrave Macmillan, Nueva York/Basingstoke.

Sen, Amartya, 2004, "Elements for a Theory of Human Rights", Philosophy and Public Affairs, vol. 32, núm. 4, pp. 315-355.

Slaughter, Joseph, 2007, Human Rights Inc. The World Novel, Narrative Form and International Law, Fordham University Press, Nueva York.

Tierney, Brian, 2001, The Idea of Natural Rights, Wm. B. Eerdmans Publishing Co., Cambridge.

Vidal, Hernán, 2009, “An Aesthetic Approach to Issues of Human Rights", Hispanic Issues On Line, vol. 4, núm. 1, pp. 14-43. 